\title{
Timeliness is Key to the Candidate Experience
}

Ann Marie Ryan

Michigan State University

Abdifatah Ahmed Ali

Michigan State University

Terry Hauer

Kelly Services

Jillyan French-Vitet

Deloitte

Follow this and additional works at: https://scholarworks.bgsu.edu/pad

Part of the Human Resources Management Commons, Industrial and Organizational Psychology

Commons, and the Other Psychology Commons

How does access to this work benefit you? Let us know!

\section{Recommended Citation}

Ryan, Ann Marie; Ali, Abdifatah Ahmed; Hauer, Terry; and French-Vitet, Jillyan (2017) "Timeliness is Key to the Candidate Experience," Personnel Assessment and Decisions: Number 3 : Iss. 1 , Article 4.

DOI: https://doi.org/10.25035/pad.2017.004

Available at: https://scholarworks.bgsu.edu/pad/vol3/iss1/4

This Main Article is brought to you for free and open access by the Journals at ScholarWorks@BGSU. It has been accepted for inclusion in Personnel Assessment and Decisions by an authorized editor of ScholarWorks@BGSU. 


\title{
Timeliness Is Key to the Candidate EXPERIENCE
}

\author{
Ann Marie Ryan ${ }^{1}$, Abdifatah Ahmed Ali, \\ Terry Hauer ${ }^{2}$ and Jillyan French-Vitet ${ }^{3}$
}

1. Michigan State University

2. Kelly Services

3. Deloitte

ABSTRACT

\section{KEYWORDS}

Recruitment, Organizational Attraction, Timeliness

\section{Eft} Effective talent attraction is a competitive advantage for organizations. This study examined the spillover effect of recruitment delays on signals important for organizational attraction. A diverse sample of 563 candidates evaluated their most recent recruitment experience. Using moderated regression and relative importance analysis, timeliness dissatisfaction dampened the positive effects of organizational prestige and opportunity to perform although these effects are greater earlier in the recruitment process. We discuss the contributions of this study and provide recommendations for recruitment practice.
"Why can't businesses take a moment to let an applicant know their status? I am not loving brands that don't let me know!” (New York Times, 2013).

Considerable research has focused on applicant reactions to hiring processes (see Hausknecht, Day, \& Thomas, 2004; Ryan \& Ployhart, 2000 for reviews). However, one of the key concerns of applicants - timely communicationis seldom integrated into studies on candidate experiences. This paper documents the critical role of satisfaction with timeliness in affecting applicant perceptions. Although some research has supported the importance of timing in communication once an application has been submitted (Becker, Connolly, \& Slaughter, 2010; Schreurs, Derous, van Hooft, Proost, \& De Witte, 2009), we examine the moderating role of timeliness satisfaction when applicants have acquired other sources of information (e.g., employer prestige, satisfaction with information provided about the organization [i.e., organization information], and interpersonal treatment) that have implications for how candidates view employers. Investigating such potential moderations is important because organizational investments to enhance a candidate's experience through engaging, high tech assessments and informative websites may be wasted if a key factor-timeliness - is not well addressed. A second contribution is to consider how the role of timeliness satisfaction and the strength of the perceptions-attractiveness relationships vary as a function of where the applicant is in the recruitment process (Uggerslev, Fassina, \& Kraichy,
2012). Although recruitment theory clearly suggests shifts in applicant expectations as their candidacy advances, studies seldom clarify what those shifts are. In the sections that follow, we draw on signaling theory and the elaboration likelihood model to outline why we might expect changes in the importance of different candidate perceptions over the course of a recruitment process.

\section{Signaling Theory and Elaboration Likelihood Model}

According to signaling theory (Spence, 1973), applicants have incomplete information regarding jobs and organizations so they utilize various signals revealed during the recruitment period to fill in gaps in knowledge (Rynes, 1991). These signals, in turn, become the basis for forming images of the organization and thus have implications for attraction (Breaugh, Macan, \& Grambow, 2008). However, signaling theory does not provide guidance as to precisely what type of signals and at what points during the process such information would have influence (Ehrhart \& Ziegert, 2005). To overcome this, signaling theory can be considered in tandem with the elaboration likelihood model.

The elaboration likelihood model (ELM) forwarded by Petty and Cacioppo (1986) allows for the identification of signals (recruiter, company website, interacting with current employees) that lead to attraction as well as explicates how initial relations change as a function of moving through the recruitment stages (i.e., application submission, interviewing, site visit). ELM postulates that persuasive communication influences attitude formation via two dis-

\section{Corresponding author:}

Abdifatah Ali

Email: aliabdi1@msu.edu

Phone: 619-788-6504 
tinct pathways: (a) The central processing route whereby individuals carefully scrutinize the information content of the message and attitude formation -- positive or negative -- is largely determined by message quality (e.g., argument strength), and (b) the peripheral processing route whereby individuals engage in surface-level processing and attitude formation occurs based on message characteristics (i.e., message length, structure) rather than content. According to ELM, an individual's motivation and ability are key determinants of the degree of elaboration that occurs. When elaboration is high, central processing is activated because of the higher motivation and ability to process the persuasive information; peripheral processing is more likely when elaboration is low (Jones, Shultz, \& Chapman, 2006; Petty \& Cacioppo, 1986).

In the next section, we review relevant literature pertaining to five well-researched signals (employer prestige, organization information, technology usability, opportunity to perform, interpersonal treatment) and incorporate signaling theory and ELM to develop specific hypotheses regarding the role of timeliness satisfaction. These signals relate to both the "what" (prestige, organizational information) and the "how" (technology, opportunity, treatment) aspects of recruitment; studies typically do not include both aspects, and so we chose what and how signals that have been supported as influencing applicant choice (see Chapman, Uggerslev, Carroll, Plasentin, \& Jones, 2005; Uggerslev et. al, 2012). We also drew from the literature on organizational justice and applicant perceptions, which is largely driven by Gilliland's (1993) model, where two of the broad categories are interpersonal treatment and formal characteristics (encompassing timeliness and opportunity to perform).

\section{Attraction Influences}

Prestige/reputation. Highhouse, Broadfoot, Yugo, and Devendorf (2009) defined employer prestige as a "global, temporally stable, evaluative judgment about a firm that is shared by multiple constituencies" (p. 783); this definition maps on to the generalized favorability dimension of firm reputation (see Lange, Lee, \& Dai, 2011 for a review). Employer prestige impacts the quality of applicants (Cable \& Turban, 2003; Turban \& Cable, 2003), and moderate relationships have been found between prestige and job pursuit intentions $(\rho=.51)$, job-organization attraction $(\rho=.48)$, and acceptance intentions ( $\rho=.41$; Chapman et al., 2005). In signaling theory terms, employer prestige works as a proxy for understanding the overall quality of the organization. As such, we expect that prestige will be positively related with organizational attraction and pursuit intentions.

Organization information. We define organization information as "the selected configuration of information conveyed through recruitment mediums" (Selden \& Orenstein, 2011; p. 210). Company websites provide mission statements, organizational history and culture, and work en- vironment information, and this has recruiting implications. For example, organizational knowledge has been found to directly relate to attitudes toward the organization and indirectly to pursuit intentions (Allen, Mahto, \& Otondo, 2007). In general, the more organizational knowledge candidates have, the greater the possibility for attraction (Allen, VanScotter, \& Otondo, 2004).

Technology usability. Technology usability relates to applicant's general impression of the application tracking system as well as their technical impression of websites, webinars, and other elements of the recruitment process. We focus on applicant's impressions of the functionality (i.e., perceived usability) of the company website (Cober, Brown, Keeping, \& Levy, 2004), but we generalize this further to include any engagement with the organization through other sources of technology as well. The perceived usability of an organization's website has been shown to affect overall level of attraction as well as likelihood to recommend the organization to friends (Cober, Brown, Levy, Cober, \& Keeping, 2003), and intentions to pursue employment have been shown to be affected by organizational website usability (Thompson, Braddy, \& Wuensch, 2008). Thus, more positive impressions of technology usability should lead to greater attraction.

Opportunity to perform. Opportunity to perform has been defined as a perception that a hiring process gives one adequate opportunity to demonstrate competence (Bauer et al., 2001; Gilliland, 1993; Schleicher, Venkatoramini, Morgeson, \& Campion, 2006). Researchers (Dineen, Noe, \& Wang, 2004; Konradt, Warszta, \& Ellwart, 2013; Schleicher et al., 2006) also have found opportunity to perform to be a key predictor of fairness perceptions. In this study, we extend consideration of opportunity to perform by examining its role as a direct predictor of outcomes, as well as examining its relative influence compared to other factors.

Interpersonal treatment. Interpersonal treatment has typically been defined in terms of warmth and respect given to applicants by those with whom they interact. Recruiter warmth has long been established as an influence on applicant decisions (Harris \& Fink, 1987; Taylor \& Bergmann, 1987). Further, interpersonal treatment has been found by some researchers to be a dominant predictor of fairness perceptions (Konradt et al., 2013) and to perhaps have a greater effect on more desirable applicants (Chapman \& Webster, 2006). Thus, we would anticipate interpersonal treatment to be a key influencer on attraction.

The Role of Timeliness and Recruitment Stage

Timeliness satisfaction. Because what is considered as timely varies based on expectations related to specific hiring processes (e.g., a multistage process will involve a longer timeline), researchers have focused on timeliness satisfaction as the perceptual variable of interest rather than a given number of days for communication to take place. In their meta-analysis, Chapman et al. (2005) found 
a moderate positive relationship between perceptions of timeliness and organizational attraction $(\rho=.46)$. Beyond main effects, Carless and Hetherington (2011) showed that perceived job and organizational characteristics partially mediated the effects of timeliness satisfaction on attraction. Consistent with signaling theory, these findings indicate that responsiveness serves as a signal to what it would be like to work for a particular company, which in turn influences attraction.

As Breaugh (2013) notes, although we presume delays serve as a signal, we need further data on how a lack of timeliness is interpreted. Scholars of the role of time in organizations have established that our ideas regarding expected durations of events and regularities in the timing of processes provide us with a sense or orderliness, reduce feelings of uncertainty, and allow planning (see Bluedorn \& DenHardt, 1988 for a review). We posit that a negative timeliness experience distorts the applicant's reactions to other signals from the organization because it does not allow for planning and can elevate uncertainty. For instance, negative reactions to untimely communication can activate fairness concerns (Gilliland, 1993), leading to individuals becoming frustrated and possibly reassessing their view of the organization. We propose that timeliness satisfaction has a key role in reducing uncertainty for applicants and thus may trigger reevaluations of other perceptions of the potential employer. Thus, the positive effects of the five attraction factors previously discussed will be dampened when timeliness satisfaction is low.

Hypothesis 1. Timeliness satisfaction will moderate the positive relationship between signals ((a) organizational prestige, (b) organization information, (c) technology usability, (d) opportunity to perform, and (e) interpersonal treatment) and organizational attraction and intentions to pursue/reapply such that weaker effects emerge when timeliness satisfaction is low.

Recruitment stage. Recent meta-analytic work has highlighted the importance of conceptualizing recruitment as a process whereby certain factors are important in one particular stage more than another (Uggerslev et al., 2012). Although we expect that a lack of timeliness will moderate the effects of various factors on attraction (Hypothesis la-e), we also expect the magnitude of that moderation to be greater for those reporting on early stages. In line with ELM and signaling theory, those applicants who have advanced further in the process will have more information about the organization from which to make judgments, and thus timeliness may not serve as critical a signaling role as it does for those who have not advanced far in the process. Note that this expectation is not dependent on whether the applicant is receiving positive or negative feedback from the organization regarding his/her status; delays in communication are interpreted as negative signals regardless of the ultimate standing of the applicant. We propose: ${ }^{1}$

Hypothesis 2. There will be a three-way interaction between signals ((a) organizational prestige, (b) organization information, (c) technology usability, and (d) opportunity to perform), timeliness satisfaction, and recruitment stage such that the magnitude of the timeliness satisfaction moderation effect will be less for those further along in the process.

\section{METHOD}

\section{Procedure}

Participants were recruited through a United States partnering employment agency by posting the survey on its online sites (i.e., agency's website, LinkedIn page, and Facebook pages). That is, job seekers regularly search these sites for information regarding potential job openings as well as tips for job search; they could voluntarily chose to take the survey regarding their job search experiences. To reduce memory distortion, participants were directed to answer questions from the perspective of the last job to which they applied, irrespective of whether they received any feedback from the organization. Because length of survey was a key concern for the partnering agency but obtaining reliable measurement was important, measures were typically adapted from established scales. Respondents were not compensated for participation.

\section{Participants}

Participants were 563 candidates who recently (less than 6 months) went through a hiring process. Of the 563 candidates, only 149 were invited for an interview to the organization to which they applied, and of those, 52 received a job offer from that same organization. Approximately $65 \%$ were female; age varied across the sample (18-25 [22.9\%], 26-35 [27.7\%], 36-45 [21.3\%], 46-55 [20.2], and above $56[8 \%]$ ), as well as race/ethnicity (White [49.8\%], Black/African-American [27.9\%], and other [22.3\%]). The majority of participants were looking for full-time permanent $(89.2 \%)$, entry-level positions $(42.1 \%)$ in a variety of industries (banking, automotive, health, retail).

\section{Measures}

All items were assessed using a 5-point Likert-type scale (from $1=$ strongly disagree to $5=$ strongly agree). A binary variable for recruitment stage was constructed for the purposes of moderation analysis $(1=$ reached the application stage; $2=$ received an interview invitation).

Prestige was assessed using four items from Highhouse, Lievens, and Sinar (2003). A sample item is, "This organization has a reputation as being an excellent employer."

Organization information was measured using three

1 Note that interpersonal treatment was only assessed for those who interviewed with an organization and thus there is no Hypothesis 2e. 
items adapted from the symbolism and credibility scale (Allen et al., 2004). A sample item is, "This organization website communicated information about the values, beliefs, and culture." We developed four additional items that captured knowledge about the organization. The four items were: "I could find the answers on the organization website to my questions"; "I could see relevant facts and figures about the organization, which were of interest to me (e.g. organization growth, finances, number of employees etc.)"; "I could find a great deal of relevant information about the daily life of an employee at this organization"; and "Overall, this organization provided me with enough information about the job." Principal Axis Factoring (PAF) with varimax rotation suggested a one-factor solution best explained the data (variance explained $=46 \%$; factor loadings ranged from .30 to .79).

Technology usability was assessed with four items. The four items were: "The application process was easy to complete and manage," "The application process did not require a lot of time from me," "Any technology that the organization has for interacting with applicants was easy to use," and "Overall, I felt comfortable with any technology the application required." PAF results suggested that a one-factor solution best explained the data (variance explained $=$ $53.3 \%$; factor loadings ranged from .52 to .86 ).

Opportunity to perform was assessed using two items that were adapted from Bauer et al., (2001). A sample item is, "I could really show my skills and abilities through this application process."

Interpersonal treatment was measured using three items that were adapted from Bauer et al., (2001). A sample item is, "The organization representatives treated applicants with respect during the interview." Participants who did not receive an interview were not asked to complete the interpersonal treatment scale, which focused on interviewing experience.

A single item was developed to capture timeliness satisfaction ("I was satisfied with the timeliness of the organization's communications with me regarding the status of my application"). Although one-item measures are viewed as less than ideal, a meta-analysis by Wanous, Reichers, and Hundy (1997) found that one-item measures of overall satisfaction in perceptions can be adequate representations.

Organizational attractiveness was assessed using threeitems from Highhouse et al., (2003). A sample item is, "For me, this organization would be a good place to work."

Intentions to pursue/reapply were assessed with five items from Highhouse et al. (2003). A sample item is, "I would exert a great deal of effort to work for this organization." We also developed and added another item to this measure ("I would reapply to this organization for other positions even if rejected for this one").

A binary variable for recruitment stage was constructed for the purposes of our moderation analysis. Stage 1 con- sisted of participants who had only reached the application stage and Stage 2 consisted of participants who had received an interview invitation.

\section{RESULTS}

\section{Preliminary Analyses}

Confirmatory factory analyses using the Mplus 6 software (Muthén \& Muthén, 1998-2010) assessed signal distinctiveness. As expected, the five-factor model had a significantly better fit than models 1-4 (see Table 1) and fit the data reasonably well $\left(\chi^{2}=714.13, \mathrm{df}=199\right.$; RMSEA $=$ $.07 ; \mathrm{CFI}=.90 ; \mathrm{SRMR}=.06$ ). According to the CFA results, the signals are distinct elements. Moreover, the intercorrelations among the five factors were small to moderate, further suggesting their uniqueness (see Table 2).

As might be expected, Table 2 also shows that means for organizational attractiveness and intention to pursue/ reapply were high and their correlation was high $(r=.81, p$ $<.01)$. To test whether these outcome measures were empirically distinguishable, we conducted a CFA. A two-factor solution $\left(\chi^{2}=142.85, \mathrm{df}=19\right)$ fit better than a one-factor solution $\left(\chi^{2}=147.93, \mathrm{df}=20\right)$ as indicated by the significant decrease in misfit $\left(\Delta \chi^{2}=5.08, \Delta \mathrm{df}=1\right)$ for the two-factor model $(\mathrm{CFI}=.95$; $\mathrm{SRMR}=.03$; RMSEA $=.12)$. Further, these findings are consistent with the measurement configuration found by Highhouse et al. (2003). Therefore, we treated these measures as separate variables.

\section{Moderation Analyses}

Tables 3-6 present the results of the moderation analyses to test hypotheses. Job offer was used as a control variable in analyses as it was expected that those receiving offers would have more positive perceptions of an organization. Organizational prestige interacted with timeliness satisfaction and recruitment stage to predict intentions to pursue/reapply $(\beta=-.38, p<.05$; see Table 3 and Figure 1$)$. For participants who were in Stage 1 (i.e., preinterview), simple slopes analysis indicated that the effect of organizational prestige on intentions to pursue/reapply was only significant when timeliness satisfaction was one SD above the mean $(\beta=.71, p<.01)$ and not when it was one SD below the mean $(\beta=-.01, n s)$. For participants who were in Stage 2 (i.e., postinterview), simple slopes analysis suggested that the effect of organizational prestige on intentions to pursue/ reapply was significant both when timeliness satisfaction was high $(\beta=.35, p<.01)$ and when it was low $(\beta=.56, p$ $<.01$ ). These results suggest that prestige may not override a lack of timely feedback early in the recruitment process; delays may be tolerated from a prestigious organization when an applicant is more invested and advanced in the process. Thus, Hypothesis 1a and Hypothesis 2a received partial support. 
TABLE 1.

Comparison of Alternative Factor Structures for Signals

\begin{tabular}{|c|c|c|c|c|c|c|}
\hline Model & Descriptives & $\chi 2 / \mathrm{df}$ & $\begin{array}{c}\Delta \chi 2 / \Delta \mathrm{df} \\
(\text { Model comparison) }\end{array}$ & RMSEA & CFI & SRMR \\
\hline Model 1 & $\begin{array}{l}\text { One factor: Organizational Prestige, Organization } \\
\text { Information, Technology Usability, Opportunity to } \\
\text { Perform, and Interpersonal Treatment }\end{array}$ & $2690.53 / 209$ & ---- & .15 & .51 & .12 \\
\hline Model 2 & $\begin{array}{l}\text { Two factor: Factor 1(Organizational Prestige, Orga- } \\
\text { nization Information, Technology Usability) Factor } \\
2 \text { (Opportunity to Perform, Interpersonal Treatment) }\end{array}$ & $2340.56 / 208$ & $349.97 / 1 *($ Model 1) & .14 & .58 & .17 \\
\hline Model 3 & $\begin{array}{l}\text { Three factor: Factor } 1 \text { (Organizational Prestige) } \\
\text { Factor } 2 \text { (Organization Information, Technology } \\
\text { Usability) Factor } 3 \text { (Opportunity to Perform, Inter- } \\
\text { personal Treatment) }\end{array}$ & $1630.18 / 206$ & $710.38 / 2 *($ Model 2$)$ & .11 & .72 & .16 \\
\hline Model 4 & $\begin{array}{l}\text { Four factor: Factor } 1 \text { (Organizational Prestige) } \\
\text { Factor } 2 \text { (Organization Information, Technology } \\
\text { Usability) Factor } 3 \text { (Opportunity to Perform) Factor } \\
4 \text { (Interpersonal Treatment) }\end{array}$ & $1172.89 / 203$ & $457.29 / 3 *($ Model 3$)$ & .09 & .81 & .08 \\
\hline Model 5 & Five factor: All constructs as theorized & $714.13 / 199$ & 458.76/4* (Model 4) & .07 & .90 & .06 \\
\hline
\end{tabular}

Note. $N=561$. RMSEA = root-mean-square error of approximation; $\mathrm{CFI}=$ comparative fit index; $\mathrm{SRMR}=$ standardized root-mean-square residual. ${ }^{*} p<.001$.

TABLE 2.

Descriptive Statistics, Reliabilities, and Intercorrelations

\begin{tabular}{|c|c|c|c|c|c|c|c|c|c|c|c|c|c|c|}
\hline & $M$ & $S D$ & 1 & 2 & 3 & 4 & 5 & 6 & 7 & 8 & 9 & 10 & 11 & 12 \\
\hline 1.Gender ${ }^{\mathrm{a}}$ & .35 & .48 & & & & & & & & & & & & \\
\hline 2.Employment status ${ }^{\mathrm{b}}$ & .37 & .48 & .02 & & & & & & & & & & & \\
\hline 3.Job offer ${ }^{\mathrm{c}}$ & .11 & .31 & -.02 & $.17 * *$ & & & & & & & & & & \\
\hline 4.Timeliness satisfaction & 3.01 & 1.20 & .02 & -.01 & $.25 * *$ & & & & & & & & & \\
\hline 5.Recruitment stage ${ }^{\mathrm{d}}$ & 1.68 & .47 & .07 & $-.12 * *$ & $-.52 * *$ & $-.33 * *$ & & & & & & & & \\
\hline 6.Organizational prestige & 3.90 & .75 & .05 & .03 & -.07 & .09 & .05 & .89 & & & & & & \\
\hline 7.Organization information & 3.63 & .66 & .04 & -.06 & -.01 & $.19 * *$ & .00 & $.50 * *$ & .84 & & & & & \\
\hline 8.Technology usability & 3.81 & .69 & -.01 & -.02 & .06 & $.22 * *$ & -.05 & $.32 * *$ & $.40 * *$ & .79 & & & & \\
\hline 9.Opportunity to perform & 3.36 & 1.28 & -.07 & .01 & $.16^{* *}$ & $.21 * *$ & $-.13 * *$ & -.03 & $.14 * *$ & $.09 *$ & .90 & & & \\
\hline 10.Interpersonal treatment & 4.01 & .79 & .05 & .06 & $.18^{*}$ & $.40 * *$ & NA & $.31 * *$ & $.40 * *$ & $.35 * *$ & .01 & .94 & & \\
\hline 11.Organizational attractiveness & 3.93 & .76 & .05 & -.01 & $-.10 *$ & $.12 *$ & $.10^{*}$ & $.50 * *$ & $.43 * *$ & $.29 * *$ & -.05 & $.46^{* *}$ & .72 & \\
\hline 12.Intentions to pursue/reapply & 4.09 & .72 & $.14^{*}$ & -.01 & -.08 & $.15^{* *}$ & $.11 *$ & $.51 * *$ & $.48 * *$ & $.30 * *$ & -.01 & $.48 * *$ & $.81 * *$ & .92 \\
\hline
\end{tabular}

Note. $N$ ranged from 431-558 (sample size is lower for the correlations with interpersonal treatment, which was only completed by stage two participants); scales ranged from $1-5 ; *^{*}<.05, * * p<.01$; NA = conditions where the samples did not overlap; coefficient alphas are presented on the diagonal; $\mathrm{a}=$ gender coded $(0=$ female, $1=$ male $)$; $\mathrm{b}=$ employment status coded $(0=$ not employed, $1=$ employed $) ; \mathrm{c}=$ job offer coded $(0=$ all others, $1=$ received job offer $) ; \mathrm{d}=$ recruitment stage coded (1 = Stage 1, 2 = Stage 2).

We found no support for a two-way or a three-way interaction with organization information (Hypotheses $1 \mathrm{~b}$ and 2b; see Table 4) as well as technology usability (Hypotheses $1 \mathrm{c}$ and 2c; see Table 5).

Table 6 shows partial support for Hypotheses 1d and $2 \mathrm{~d}$ regarding the two-way and three-way interaction with opportunity to perform. Opportunity to perform interacted with timeliness satisfaction to predict organizational at- tractiveness $(\beta=.46, p<.05$; see Figure 2$)$. Simple slopes analysis indicated that the effect of opportunity to perform on organizational attractiveness was significant only when timeliness satisfaction was high $(\beta=.40, p<.01)$ but not when it was low ( $\beta=-.06$, ns), supporting Hypothesis $4 \mathrm{a}$. Opportunity to perform interacted with timeliness satisfaction and recruitment stage to predict organizational attractiveness $(\beta=-.41, p<.05$; see Figure 3$)$. For participants 
who were preinterview, simple slopes analysis indicated that the effect of opportunity to perform on organizational attractiveness was significant both when timeliness satisfaction was one SD above the mean $(\beta=.57, p<.01)$ as well as one SD below the mean $(\beta=-.62, p<.01)$, although the sign of the relationship reversed. However, for participants who were in postinterview, simple slopes analysis suggested that the effect of opportunity to perform on organization- al attractiveness was not significant when timeliness satisfaction was one SD above the mean $(\beta=-.03$, ns) as well as when it was one SD below the mean $(\beta=-.14, \mathrm{~ns})$.

Finally, Hypothesis 1e, which posited that timeliness satisfaction would moderate the relationship between interpersonal treatment and organizational attractiveness and intentions to pursue/reapply, was not supported (see Table 7).

TABLE 3.

Organizational Prestige Interacting With Timeliness Satisfaction and Recruitment Stage to Predict Organizational Attractiveness and Intentions to Pursue/Reapply

\begin{tabular}{|c|c|c|c|c|}
\hline \multirow[b]{2}{*}{ Predictor } & \multicolumn{2}{|c|}{ Organizational attractiveness } & \multicolumn{2}{|c|}{ Intentions to pursue/reapply } \\
\hline & $\beta_{\text {Initial }}{ }^{a}$ & $\beta_{\text {Final }}^{\mathrm{b}}$ & $\beta_{\text {Initial }}{ }^{a}$ & $\beta_{\text {Final }}^{\mathrm{b}}$ \\
\hline \multicolumn{5}{|l|}{ Step 1: Main effects } \\
\hline Job Offer ${ }^{c}$ & -.03 & -.05 & .01 & .00 \\
\hline Organizational Prestige & $.48 * *$ & .34 & $.48^{* *}$ & .35 \\
\hline Timeliness Satisfaction & $.12^{* *}$ & $.58 * *$ & $.16^{* *}$ & $.48^{* *}$ \\
\hline Recruitment Stage $^{\mathrm{d}}$ & $.39^{*}$ & $.56^{* *}$ & $.52 * *$ & $.66^{* *}$ \\
\hline$F(\Delta F)$ & \multicolumn{2}{|c|}{$30.91 * *$} & \multicolumn{2}{|c|}{$32.74 * *$} \\
\hline$R^{2}\left(\Delta R^{2}\right)$ & \multicolumn{2}{|c|}{$.27 * *$} & \multicolumn{2}{|c|}{$.28 * *$} \\
\hline \multicolumn{5}{|l|}{ Step 2: Two-way interactions } \\
\hline Organizational Prestige $\times$ Timeliness Satisfaction & .03 & .20 & -.08 & .29 \\
\hline Organizational Prestige $\times$ Recruitment Stage & -.06 & .12 & -.03 & .11 \\
\hline Timeliness Satisfaction $\times$ Recruitment Stage & $-.45 * *$ & $-.47 * *$ & -.27 & -.29 \\
\hline$F(\Delta F)$ & \multicolumn{2}{|c|}{$(2.28)$} & \multicolumn{2}{|c|}{$(2.42)$} \\
\hline$R^{2}\left(\Delta R^{2}\right)$ & \multicolumn{2}{|c|}{$(.01)$} & \multicolumn{2}{|c|}{$(0.01)$} \\
\hline \multicolumn{5}{|l|}{ Step 3: Three-way interaction } \\
\hline $\begin{array}{l}\text { Organizational Prestige } \times \text { Timeliness Satisfaction } \times \\
\text { Recruitment Stage }\end{array}$ & -.17 & -.17 & $-.38^{*}$ & $-.38^{*}$ \\
\hline$F(\Delta F)$ & \multicolumn{2}{|c|}{$(0.80)$} & \multicolumn{2}{|c|}{$(4.22)^{*}$} \\
\hline$R^{2}\left(\Delta R^{2}\right)$ & \multicolumn{2}{|c|}{$(.00)$} & \multicolumn{2}{|c|}{$(.01)^{*}$} \\
\hline
\end{tabular}

Note. $N=433 ; \mathrm{a}=$ beta coefficient of the particular step at which the variable initially entered the equation; $\mathrm{b}=$ beta coefficient in the final step; $\mathrm{c}=$ job offer coded $(0=$ all others, $1=$ received job offer $) ; \mathrm{d}=$ recruitment stage coded $(1=$ Stage 1,2 = Stage 2$) ;{ }^{*} p<.05,{ }^{* *} p<.01$.

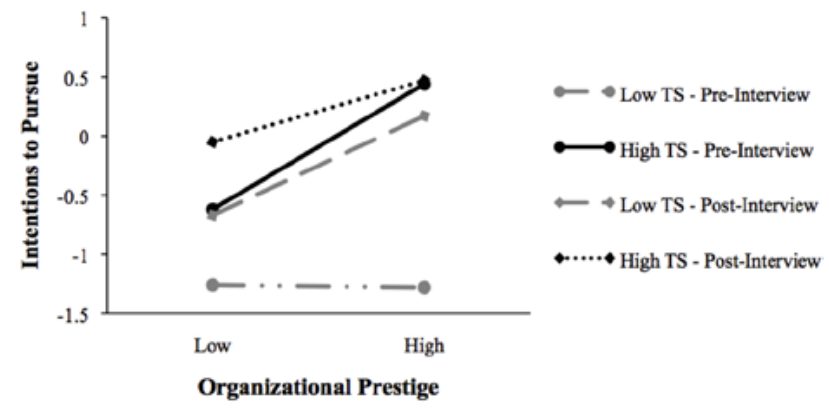

FIGURE 1. Organizational prestige interacting with timeliness satisfaction and recruitment stage to predict intentions to pursue/reapply.

Note . TS = timeliness satisfaction. All outcome variables were mean centered. 
TABLE 4.

Organization Information Interacting With Timeliness Satisfaction and Recruitment Stage to Predict Organizational Attractiveness and Intentions to Pursue/Reapply

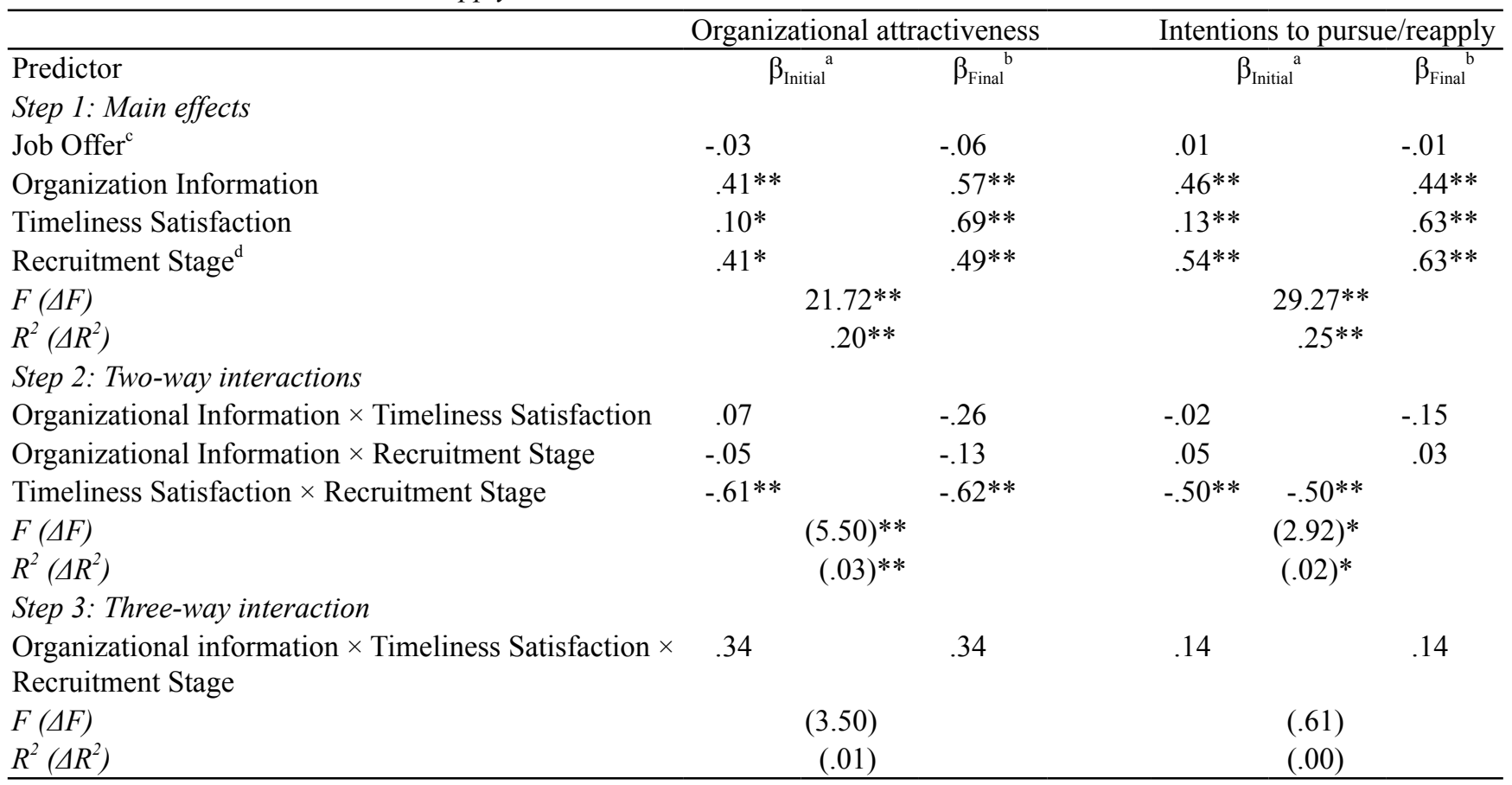

Note. $N=432 ; \mathrm{a}=$ beta coefficient of the particular step at which the variable initially entered the equation; $\mathrm{b}=$ beta coefficient in the final step; $\mathrm{c}=$ job offer coded $(0=$ all others, $1=$ received job offer $) ; \mathrm{d}=$ recruitment stage coded $(1=$ Stage 1,2 $=$ Stage 2$) ; * p<.05, * * p<.01$.

TABLE 5 .

Technology Usability Interacting With Timeliness Satisfaction and Recruitment Stage to Predict Organizational Attractiveness and Intentions to Pursue/Reapply

\begin{tabular}{|c|c|c|c|c|}
\hline \multirow[b]{2}{*}{ Predictor } & \multicolumn{2}{|c|}{ Organizational attractiveness } & \multicolumn{2}{|c|}{ Intentions to pursue/reapply } \\
\hline & $\beta_{\text {Initial }}{ }^{a}$ & $\beta_{\text {Final }}^{\mathrm{b}}$ & $\beta_{\text {Initial }}{ }^{\mathrm{a}}$ & $\beta_{\text {Final }}^{b}$ \\
\hline \multicolumn{5}{|l|}{ Step 1: Main effects } \\
\hline Job Offer ${ }^{c}$ & -.08 & -.10 & -.04 & -.06 \\
\hline Technology Usability & $.27 * *$ & .27 & $.26 * *$ & .15 \\
\hline Timeliness Satisfaction & $.11 *$ & $.69^{* *}$ & $.16^{* *}$ & $.66^{* *}$ \\
\hline Recruitment Stage $^{\mathrm{d}}$ & $.44^{* *}$ & $.55^{* *}$ & $.57^{* *}$ & $.66^{* *}$ \\
\hline$F(\Delta F)$ & \multicolumn{2}{|c|}{$10.21 * *$} & \multicolumn{2}{|c|}{$11.04 * *$} \\
\hline$R^{2}\left(\Delta R^{2}\right)$ & \multicolumn{2}{|c|}{$.11 * *$} & \multicolumn{2}{|c|}{$.12 * *$} \\
\hline \multicolumn{5}{|l|}{ Step 2: Two-way interactions } \\
\hline Technology Usability $\times$ Timeliness Satisfaction & .09 & -.16 & .04 & -.15 \\
\hline Technology Usability $\times$ Recruitment Stage & .05 & .02 & .15 & .12 \\
\hline Timeliness Satisfaction $\times$ Recruitment Stage & $-.57 * *$ & $-.60 * *$ & $-.49 *$ & $-.50 * *$ \\
\hline$F(\Delta F)$ & \multicolumn{2}{|c|}{$(4.39)^{* *}$} & \multicolumn{2}{|c|}{$(2.24)$} \\
\hline$R^{2}\left(\Delta R^{2}\right)$ & \multicolumn{2}{|c|}{$(.03)^{* *}$} & \multicolumn{2}{|c|}{$(.01)$} \\
\hline \multicolumn{5}{|l|}{ Step 3: Three-way interaction } \\
\hline $\begin{array}{l}\text { Technology Usability } \times \text { Timeliness Satisfaction } \\
\times \text { Recruitment Stage }\end{array}$ & .25 & .24 & .20 & .20 \\
\hline$F(\Delta F)$ & \multicolumn{2}{|c|}{$(1.75)$} & \multicolumn{2}{|c|}{$(1.03)$} \\
\hline$R^{2}\left(\Delta R^{2}\right)$ & \multicolumn{2}{|c|}{$(.00)$} & \multicolumn{2}{|c|}{$(.00)$} \\
\hline
\end{tabular}

Note. $N=429 ; \mathrm{a}=$ beta coefficient of the particular step at which the variable initially entered the equation; $\mathrm{b}=$ beta coefficient in the final step; $\mathrm{c}=$ job offer coded $(0=$ all others, $1=$ received job offer $) ; \mathrm{d}=$ recruitment stage coded $(1=$ Stage 1,2 = Stage 2); ${ }^{*} p<.05,{ }^{* *} p<.01$. 
TABLE 6.

Opportunity to Perform Interacting With Timeliness Satisfaction and Recruitment Stage to Predict Organizational Attractiveness and Intentions to Pursue/Reapply

\begin{tabular}{|c|c|c|c|c|c|}
\hline \multirow[b]{2}{*}{ Predictor } & \multicolumn{2}{|c|}{ Organizational attractiveness } & \multicolumn{3}{|c|}{ Intentions to pursue/reapply } \\
\hline & $\beta_{\text {Initial }}{ }^{a}$ & \multirow[t]{2}{*}{$\beta_{\text {Final }} \mathrm{b}$} & \multicolumn{2}{|c|}{$\beta_{\text {Initial }}^{\mathrm{a}}$} & $\beta_{\text {Final }}{ }^{b}$ \\
\hline \multicolumn{5}{|l|}{ Step 1: Main effects } & \\
\hline Job Offer ${ }^{c}$ & -.07 & -.10 & -.03 & & -.06 \\
\hline Opportunity to Perform & -.06 & -.06 & -.04 & & -.02 \\
\hline Timeliness Satisfaction & $.18 * *$ & $.89 * *$ & $.22 * *$ & & $.82 * *$ \\
\hline Recruitment Stage $^{\mathrm{d}}$ & $.47 *$ & $.72 * *$ & $.60 * *$ & & $.81 * *$ \\
\hline$F(\Delta F)$ & \multicolumn{2}{|c|}{$3.78 * *$} & \multicolumn{3}{|c|}{$4.70 * *$} \\
\hline$R^{2}\left(\Delta R^{2}\right)$ & \multicolumn{2}{|c|}{$.04 * *$} & \multicolumn{3}{|c|}{$.05 * *$} \\
\hline \multicolumn{6}{|l|}{ Step 2: Two-way interactions } \\
\hline Opportunity to Perform $\times$ Timeliness Satisfaction & .06 & $.46^{*}$ & .03 & & .40 \\
\hline Opportunity to Perform $\times$ Recruitment Stage & -.12 & -.03 & -.13 & & -.05 \\
\hline Timeliness Satisfaction $\times$ Recruitment Stage & $-.61 * *$ & $-.70 * *$ & $-.51 * *$ & $-.59 * *$ & -.29 \\
\hline$F(\Delta F)$ & \multicolumn{2}{|c|}{$(4.61)^{* *}$} & \multicolumn{3}{|c|}{$(3.08)^{* *}$} \\
\hline$R^{2}\left(\Delta R^{2}\right)$ & \multicolumn{2}{|c|}{$(.03)^{* *}$} & \multicolumn{3}{|c|}{$(.02)^{* *}$} \\
\hline \multicolumn{6}{|l|}{ Step 3: Three-way interaction } \\
\hline $\begin{array}{l}\text { Opportunity to Perform } \times \text { Timeliness Satisfaction } \\
\times \text { Recruitment Stage }\end{array}$ & $-.41 *$ & $-.41 *$ & -.38 & & -.38 \\
\hline$F(\Delta F)$ & \multicolumn{2}{|c|}{$(4.07)^{*}$} & \multicolumn{3}{|c|}{$(3.36)$} \\
\hline$R^{2}\left(\Delta R^{2}\right)$ & \multicolumn{2}{|c|}{$(.01)^{*}$} & \multicolumn{3}{|c|}{$(.01)$} \\
\hline
\end{tabular}

Note. $N=435 ; \mathrm{a}=$ beta coefficient of the particular step at which the variable initially entered the equation; $\mathrm{b}=$ beta coefficient in the final step; $\mathrm{c}=$ job offer coded $(0=$ all others, $1=$ received job offer $) ; \mathrm{d}=$ recruitment stage coded $(1=$ Stage 1,2 Stage 2$) ; * p<.05, * * p<.01$.

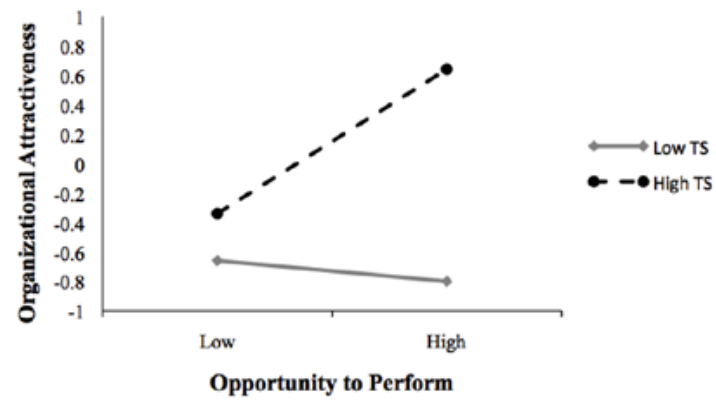

FIGURE 2. Opportunity to perform interacting with timeliness satisfaction to predict organizational attractiveness. Note. TS $=$ timeliness satisfaction.

\section{Relative Importance Analysis}

To understand the unique contributions of signals over time, we used relative weights analysis using software developed by Tonidandel and LeBreton (see http://relativeimportance.davidson.edu/). Relative weight estimates and their corresponding 95\% confidence interval were generated after a bootstrapping process with 10,000 iterations. Two separate analyses were conducted based on recruitment stage. Relative weight coefficients are considered statistically significant when the confidence interval itself

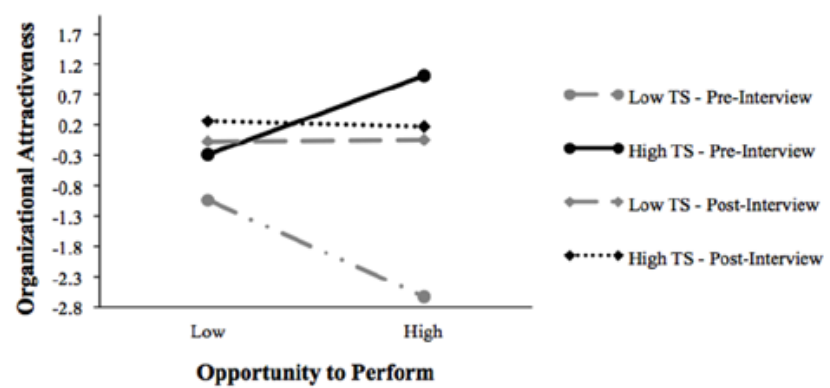

FIGURE 3. Opportunity to perform interacting with timeliness satisfaction and recruitment stage to predict organizational attractiveness.

Note. $\mathrm{TS}=$ timeliness satisfaction.

for the relative weights does not contain zero (Tonidandel, LeBreton, \& Johnson, 2009). For Stage 1, organizational prestige, organization information, and technology usability were important predictors, accounting for $59 \%, 24 \%$, and $14 \%$ (respectively) of the predictable variance in organizational attractiveness and 46\%, 39\%, and 13\% (respectively) of the variance in pursuit intentions (see Table 8). For Stage 2 , organization information, organizational prestige, interpersonal treatment, and technology usability were important predictors, accounting for $34 \%, 32 \%, 24 \%$, and $10 \%$ 
TABLE 7.

Interpersonal Treatment Interacting With Timeliness Satisfaction to Predict Organizational Attractiveness and Intentions to Pursue/Reapply

\begin{tabular}{|c|c|c|c|c|}
\hline & \multicolumn{2}{|c|}{ Organizational attractiveness } & \multicolumn{2}{|c|}{ Intentions to pursue/reapply } \\
\hline Predictor & $\beta_{\text {Initial }}{ }^{\mathrm{a}}$ & $\beta_{\text {Final }}^{\mathrm{b}}$ & $\beta_{\text {Initial }}{ }^{a}$ & $\beta_{\text {Final }}^{\mathrm{b}}$ \\
\hline \multicolumn{5}{|l|}{ Step 1: Main effects } \\
\hline Job Offer ${ }^{c}$ & $-.23 *$ & $-.23 *$ & -.15 & -.15 \\
\hline Interpersonal Treatment & $.42 * *$ & $.44 * *$ & $.43 * *$ & $.47 * *$ \\
\hline Timeliness Satisfaction & $.27 * *$ & $.27 * *$ & $.25 * *$ & $.25 * *$ \\
\hline$F(\Delta F)$ & \multicolumn{2}{|c|}{$14.56 * *$} & \multicolumn{2}{|c|}{$14.12 * *$} \\
\hline$R^{2}\left(\Delta R^{2}\right)$ & \multicolumn{2}{|c|}{$.28 * *$} & \multicolumn{2}{|c|}{$.27 * *$} \\
\hline \multicolumn{5}{|l|}{ Step 2: Two-way interactions } \\
\hline Interpersonal Treatment $\times$ Timeliness Satisfaction & .07 & -.26 & -.02 & -.15 \\
\hline$F(\Delta F)$ & \multicolumn{2}{|c|}{$(5.50)^{* *}$} & \multicolumn{2}{|c|}{$(2.92)^{*}$} \\
\hline$R^{2}\left(\Delta R^{2}\right)$ & \multicolumn{2}{|c|}{$(.01)$} & \multicolumn{2}{|c|}{$(.00)$} \\
\hline
\end{tabular}

Note. $N=138$; $\mathrm{a}=$ beta coefficient of the particular step at which the variable initially entered the equation; $\mathrm{b}=\mathrm{beta}$ coefficient in the final step; $\mathrm{c}=$ job offer coded $(0=$ all others, $1=$ received job offer $) ; \mathrm{d}=$ recruitment stage coded $(1=$ Stage 1,2 Stage 2); $* p<.05, * * p<.01$.

TABLE 8.

Relative Weight Results for Stage 1 Applicants

\begin{tabular}{|c|c|c|c|c|c|}
\hline \multirow[b]{2}{*}{ Predictor } & \multicolumn{5}{|c|}{$95 \%$ Confidence interval for relative weights } \\
\hline & $\beta$ & Relative weights & $\%$ of $R^{2}$ & Lower limit & Upper limit \\
\hline \multicolumn{6}{|c|}{ Outcome: Organizational attractiveness } \\
\hline Organizational prestige & $.38 * *$ & $.17 *$ & 58.84 & .09 & .26 \\
\hline Organization information & $.16^{*}$ & $.07 *$ & 23.83 & .03 & .13 \\
\hline Technology usability & $.13 *$ & $.04 *$ & 13.89 & .01 & .09 \\
\hline Opportunity to perform & -.05 & .01 & 3.42 & .00 & .04 \\
\hline \multicolumn{6}{|c|}{ Outcome: Intentions to pursue/reapply } \\
\hline Organizational prestige & $.29 * *$ & $.15^{*}$ & 45.66 & .07 & .23 \\
\hline Organization information & $.31 * *$ & $.13^{*}$ & 38.85 & .07 & .20 \\
\hline Technology usability & $.11^{*}$ & $.04 *$ & 13.47 & .01 & .09 \\
\hline Opportunity to perform & -.05 & .01 & 2.01 & -.01 & .03 \\
\hline
\end{tabular}

Note. $N=291$; Number of bootstrapping $=10,000$; Relative weight values are bias corrected accelerated estimates. $* p<.05$, $* * p<.01$.

respectively of the predictable variance in organizational attractiveness. For pursuit intentions, only organizational prestige, interpersonal treatment, and organization information were significant predictors, accounting for $33 \%, 31 \%$, and $28 \%$, respectively (see Table 9 ).

\section{Additional Analysis}

We separated the second-stage group to those candidates who received a job offer $(N=52)$ versus those who did not, and the only significant relationships that emerged were for opportunity to perform and interpersonal treatment. Those who received a job offer felt they had greater opportunities to perform $(r=.20, p<.05)$ as well as better interpersonal treatment $(r=.18, p<.05)$ during the hiring process.

\section{DISCUSSION}

This study demonstrated that a lack of timeliness in contacting applicants can override other positive perceptions, although this was not true for all perceptions or at all points in the hiring process. Our findings also indicate that there is variance in the importance of perceptions across stages, with organizational prestige viewed as less influential and information about the organization viewed as more important as individuals progress forward as job candidates. It is important to reiterate that these findings are controlling for job offer; that is, they apply to both accepted and rejected applicants. This study extends knowledge by showing that dissatisfaction with timeliness also can dampen other positive impressions. Specifically, the positive impact of a 
TABLE 9.

Relative Weight Results for Stage 2 Applicants

\begin{tabular}{|c|c|c|c|c|c|}
\hline \multirow[b]{2}{*}{ Predictor } & \multicolumn{5}{|c|}{$95 \%$ Confidence interval for relative weights } \\
\hline & $\beta$ & Relative weights & $\%$ of $R^{2}$ & Lower limit & Upper limit \\
\hline \multicolumn{6}{|c|}{ Outcome: Organizational attractiveness } \\
\hline Organizational prestige & $.31 * *$ & $.14 *$ & 31.50 & .07 & .25 \\
\hline Organization information & $.34 * *$ & $.15^{*}$ & 33.71 & .08 & .24 \\
\hline Technology usability & .04 & $.04 *$ & 9.61 & .01 & .11 \\
\hline Opportunity to perform & .03 & .00 & .79 & -.01 & .04 \\
\hline Interpersonal treatment & $.28 * *$ & $.11 *$ & 24.4 & .04 & .21 \\
\hline \multicolumn{6}{|c|}{ Outcome: Intentions to pursue/reapply } \\
\hline Organizational prestige & $.33 * *$ & $.14^{*}$ & 33.30 & .05 & .26 \\
\hline Organization information & $.28 * *$ & $.12 *$ & 28.04 & .05 & .20 \\
\hline Technology usability & -.04 & .03 & 6.53 & -.01 & .08 \\
\hline Opportunity to perform & .04 & .01 & 1.56 & -.02 & .05 \\
\hline Interpersonal treatment & $.33 * *$ & $.13 *$ & 30.57 & .05 & .23 \\
\hline
\end{tabular}

Note. $N=136$; Number of bootstrapping $=10,000$; Relative weight values are bias corrected accelerated estimates. $* p<.05$, $* * p<.01$.

prestigious employer brand, which was the most important influence early in the process according to our analysis, is depressed when an organization is not timely in communications with applicants. Although Sumanth and Cable (2011) showed that a high status organization can be more selective and have more demanding hiring methods than other organizations without harming attraction to the organization, their focus was on procedural justice perceptions. Our results suggest that individuals also remain attracted to high prestige employers but that a lack of timeliness does affect the level of attraction. We were unable, however, to consider which types of applicants (high versus low quality) were most affected. An interesting direction for future research would be to consider more systematically, as Sumanth and Cable did, how organizational status and individual personal status both affect "tolerance" for various selection and recruitment activities; that is, are high quality applicants' perceptions even more influenced by a lack of timeliness than applicants with less to offer?

Our relative weights analyses suggest opportunity to perform was less important to attraction and intentions than other signals. Studies assessing opportunity to perform perceptions typically do so in the context of specific assessments and the hiring process of single organizations; our sample varied widely in experiences of types of selection processes and thus also varied widely in their perceptions. Given that a portion of our sample likely completed an online application but nothing further, their perceptions of opportunity may be even more limited than those who at least get to complete some form of test or assessment (Konradt et al., 2013). However, we did find interactive effects for opportunity to perform such that applicants reported higher attractiveness in hiring situations where they felt they could demonstrate their competencies and the organization's com- munication efforts were timely, suggesting that this is still a useful factor to consider in designing processes to attract applicants, especially at early stages.

This study had a number of strengths and limitations. The sample was diverse demographically as well as in types of jobs sought and in whether the job seekers were employed or unemployed. The ability to look at job seekers at different stages in the recruitment process was also a plus. In our sample, $32 \%(N=149)$ were invited for an interview, and of those applicants, $35.9 \%(N=52)$ received a job offer. Note that we did, however, control for job offer and stage in our analyses. Respondents were asked to respond in terms of their most recent job application, which may have helped with accuracy of recall. Although our measures were adapted from existing, validated scales and evidenced adequate reliabilities, one limitation was the need for a short survey that job seekers would voluntarily complete. Common method variance is a potential concern with single survey data collections; however, CFA support for the five-factor model indicates respondents were differentiating among constructs, lessening concerns (see Aquino, Lewis \& Bradfield, 1999; Sweeney \& McFarlin, 1997 for similar arguments). Further, the interaction findings would be unlikely if common method variance were a major concern (Siemson, Roth, \& Oliveira, 2010). However, we must acknowledge that studying the dynamic nature of applicant perceptions across the recruitment process would require assessing those perceptions longitudinal rather than retrospectively as was done here; future research that adopts such designs can determine whether findings here regarding change according to stage are upheld. Finally, we note that the elaboration likelihood model informed our thinking, but there has been recent debate regarding individual difference moderators of elaboration (see for example Ebersole, et al., 2016; Luttrell, 
Petty \& Xu, 2017); further research may wish to dig deeper into when individual differences in ability, motivation, and other characteristics play a role in the extent of elaboration. We also note that because we were interested in looking at job seekers applying for a wide variety of organizations, we ended up with a binary stage variable; with a specific organization, one might be able to look at more fine-grained stages (e.g., application screen, phone interview, assessments, etc.).

One obvious practical implication would be to ensure timely communication with applicants. This is not quite as simple as it sounds because what is viewed as "timely" is not consistent across jobs and industries. Applicants differ in their expectations regarding the frequency and speed of communication (Ryan \& Huth, 2008); with technological advances individuals likely expect quicker contact from organizations (Oracle, 2012). The key for organizations is not to necessarily be the fastest in decision making but to manage expectations well by communicating clearly when applicants are likely to hear back and to follow through with any promised communication. Being timely is not about the time elapsed since an interview or other evaluative component but about managing timing expectations and communicating well. Organizations might "audit" processes to improve perceptions of timeliness, whether it be through increasing efficiencies, clarifying process timing, or adopting effective communication strategies when unanticipated delays do arise.

Future research would benefit from a longitudinal within-person design to examine changes in information processing across the recruitment stages (Uggerslev et al., 2012). In particular, applicant reactions research might benefit from a greater integration of frameworks other than organizational justice, which predominates work in the area. For example, a signaling theory framework might suggest a different approach and attention to different features of the recruitment environment as signals attended to by applicants (see Bangerter, Roulin \& Konig, 2012 for a good theoretical integration of signaling theory and employee selection). Greater attention to the cognitive processes underlying applicant processing of information, via the elaboration likelihood model or other frameworks, might yield better insights into what information applicants attend to and when they do so. Another possibility is to consider a lack of timeliness as a "violation" or "breach" of the obligations in the expected relationship between applicants and organizations. Ryan (2012) noted the extent of effects of such a breach will depend on whether a delay in communication is explained, and such a breach might be considered a violation when applicants never hear back from the organization at all. Finally, reactions to delays may be influenced by an individual's temporal focus; Shipp, Edwards, and Lambert (2009) suggest past-focused individuals may react more negatively to psychological contract violations.
In conclusion, this study demonstrated the importance of keeping applicants satisfied with the timing of communication, highlighted how timeliness may affect other factors known to be important for attraction, and also showed that these effects may differ depending on recruitment stage. Overall, organizations need to have diagnostic systems to make sure their entire process is designed to maximize applicant attraction.

\section{REFERENCES}

Allen, D. G., Mahto, R. V., \& Otondo, R. F. (2007). Web-based recruitment: Effects of information, organizational brand, and attitudes toward a web site on applicant attraction. Journal of Applied Psychology, 92, 1696-1708.

Allen, D. G., Van Scotter, J. R., \& Otondo, R. F. (2004). Recruitment communication media: Impact on prehire outcomes. Personnel Psychology, 57, 143-171.

Aquino, K., Lewis, M. U., \& Bradfield, M. (1999). Justice constructs, negative affectivity, and employee deviance: A proposed model and empirical test. Journal of Organizational Behavior, 20, 1073-1091

Bangerter, A., Roulin, N. \& Konig, CJ (2012). Personnel selection as a signaling game. Journal of Applied Psychology, 97, 719-738.

Bauer, T. N., Truxillo, D. M., Sanchez, R. J., Craig, J. M., Ferrara, P., \& Campion, M. A. (2001). Applicant reactions to selection: Development of the selection procedural justice scale (SPJS). Personnel Psychology, $54,388-420$.

Becker, W. J., Connolly T., \& Slaughter, J. E. (2010). The effect of job offer timing on offer acceptance, performance, and turnover. Personnel Psychology, 63, 223-241.

Bludedorn, A. C. \& Denhardt, R. B. (1988). Time and organizations. Journal of Management, 14, 299-320.

Breaugh, J. A. (2013). Employee recruitment. Annual Review of Psychology, 64, 389-416.

Breaugh, J. A., Macan, T. H., \& Grambow, D. M. (2008). Employee recruitment: Current knowledge and directions for future research. In G. P. Hodgkinson \& J. K. Ford (Eds.), International review of industrial and organizational psychology, (Vol. 23, pp. 45-82). New York, NY: John Wiley \& Sons.

Cable, D. M., \& Turban, D. B. (2003). The value of organizational image in the recruitment context: $A$ brand-equity perspective. Journal of Applied Social Psychology, 33, 2244-2266.

Carless, S. A., \& Hetherington, K. (2011). Understanding the applicant recruitment experience: Does timeliness matter? International Journal of Selection and Assessment, 19, 105-108.

Chapman, D. S., Uggerslev, K. L., Carroll, S. A., Piasentin, K. A., \& Jones, D. A. (2005). Applicant attraction to organizations and job choice: A meta-analytic review of the correlates of recruiting outcomes. Journal of 
Applied Psychology, 90, 928-944.

Chapman D., \& Webster J. (2006). Toward an integrated model of applicant reactions and job choice. International Journal of Human Resource Management, 17, 1032-1057.

Cober, R. T., Brown, D. J., Keeping, L. M., \& Levy, P. E. (2004). Recruitment on the net: How do organizational web site characteristics influence applicant attraction? Journal of Management, 30, 623-646.

Cober, R. T., Brown, D. J., Levy, P., Cober, A. B., \& Keeping, L. M. (2003). Organizational web sites: Web site content and style as determinants of organizational attraction. International Journal of Selection and Assessment, 11, 158-169.

Dineen, B. R., Noe, R. A., \& Wang, C (2004). Perceived fairness of web-based applicant screening procedures: Weighing rules of justice and the role of individual differences. Human Resource Management Journal, 43, 127-145.

Ebersole, C. R., Atherton, O. E., Belanger, A. L., Skulborstad, H. M., Allen, J. M., Banks, J. B., Nosek, B. A. (2016). Many labs 3: Evaluating participant pool quality across the academic semester via replication. Journal of Experimental Social Psychology, 67, 68-82

Ehrhart, K. H., \& Ziegert, J. C. (2005). Why are individuals attracted to organizations? Journal of Management, 31, 901-919.

Gilliland, S. W (1993). The perceived fairness of selection systems: an organizational justice perspective. Academy of Management Review, 18, 694-734.

Harris, M. M., \& Fink, L. S. (1987). A field study of applicant reactions to employment opportunities: Does the recruiter make a difference? Personnel Psychology, 40, 765-784.

Hausknecht, J. P., Day, D. V. \& Thomas, S. C. (2004). Applicant reactions to selection procedures: An updated model and meta-analysis, Personnel Psychology, 57, 639-683.

Highhouse, S., Broadfoot, A., Yugo, J. E., \& Devendorf, S. A. (2009). Examining corporate reputation judgments with generalizability theory. Journal of Applied Psychology, 94, 782-789.

Highhouse, S., Lievens, F., \& Sinar, E. F. (2003). Measuring attraction to organizations. Educational and Psychological Measurement, 63, 986-1001.

Jones D. A., Shultz, J. W., \& Chapman, D. S. (2006). Recruiting through job advertisements: The effects of cognitive elaboration on decision making. International Journal of Selection and Assessment, 14, 167-179.

Konradt, U., Warszta, T., \& Ellwart, T. (2013). Fairness perceptions in web-based selection: Impact on applicants' pursuit intentions, recommendation intentions, and intentions to reapply. International Journal of Selection and Assessment, 21, 155-169.

Lange, D., Lee, P. M., \& Dai, Y. (2011). Organizational reputation: An overview. Journal of Management, 37, 153-184.

Luttrell, A., Petty, R. E., \& Xu, M. (2017). Replicating and fixing failed replications: The case of need for cognition and argument quality, Journal of Experimental Social Psychology, 69, 178-183.

Muthén, L. K., \& Muthén, B. O. (1998-2010). Mplus user's guide, sixth edition. Los Angeles, CA: Muthén \& Muthén.

New York Times. (2013, September 23). Ask question about job hunting. The New York Times. Retrieved from http://www.nytimes.com/2013/09/24/business/ smallbusiness/your-questions-on-job-hunting.html

Oracle. (2012). The future of talent management: Underlying drivers of change (White paper). Retrieved from: http://www.oracle.com/us/media1/future-talentmgmt-change-drivers-1676642.pdf

Petty, R. E., \& Cacioppo, J. T. (1986). The elaboration likelihood model of persuasion. In L. Berkowitz (Ed.), Advances in experimental social psychology (Vol. 19, pp. 117-146). New York, NY: Academic Press.

Ryan, A. M. (2012). AOR and EOR: What's the connection? In L. M. Shore, J. A-M. Coyle Shapiro, \& L. E. Tetrick (Eds.), Understanding the employee-organization relationship: Applications for the 21st century (pp. 363-389). Florence, KY: Taylor and Francis.

Ryan, A. M., \& Huth, M. (2008). Not much more than platitudes? A critical look at the utility of candidate reactions research. Human Resource Management Review, 18, 119-132

Ryan, A. M., \& Ployhart, R. E. (2000). Applicants' perceptions of selection procedures and decisions: $A$ critical review and agenda for the future. Journal of Management, 26, 565-606.

Rynes, S. L. (1991) Recruitment, job-choice, and post-hire consequences: A call for new research directions. In M. D. Dunnette, \& L. M. Hough, (Eds), Handbook of industrial and organizational psychology (2nd edition, pp. 399-444). Palo Alto, CA: Consulting Psychologists Press.

Schleicher D. J., Venkataramani, V., Morgeson, F. P., \& Campion, M. A. (2006). So you didn't get the job...now what do you think? Examining opportunity-to-perform fairness perceptions. Personnel Psychology, 59, 559590.

Schreurs, B., Derous, E., Van Hooft, E. A., Proost, K., \& De Witte, K. (2009). Predicting applicants' job pursuit behavior from their selection expectations: The mediating role of the theory of planned behavior. Journal of Organizational Behavior, 30, 761-783.

Selden, S., \& Orenstein, J. (2011). Content, usability, and innovation: An evaluative methodology for government recruiting websites. Review of Public Personnel Administration, 31, 209-223.

Shipp, A. J, Edwards, J. R. \& Lambert, L. S. (2009). Conceptualization and measurement of temporal focus: The subjective experience of the past, present, and future. Organizational Behavior and Human Decision Processes, 110, 1-22.

Siemsen, E., Roth, A. \& Oliveira, P. (2010). Common method bias in regression models with linear, quadratic, and interaction effects. Organizational Research Methods, 13, 456-476. 
Spence, M. (1973) Job market signaling. The Quarterly Journal of Economics, 87, 355-374.

Sumanth, J. J. \& Cable, D. M. (2011). Status and organizational entry: How organizational and individual status affect justice perceptions of hiring systems. Personnel Psychology, 64, 963-1000.

Sweeney, P. D., \& McFarlin, D. B. (1997). Process and outcome: Gender differences in the assessment of justice. Journal of Organizational Behavior, 18, 83-98.

Taylor, M. S., \& Bergmann, T. J. (1987). Organizational recruitment activities and applicants' reactions at different stages of the recruitment process. Personnel Psychology, 40, 261-285.

Thompson, L. F., Braddy, P. W., \& Wuensch, K. L. (2008). E-recruitment and the benefits of organizational web appeal. Computers in Human Behavior, 24, 2384-2398.

Tonidandel, S., LeBreton, J. M., \& Johnson, J. W. (2009). Determining the statistical significance of relative weights. Psychological Methods, 14, 387-399.

Turban, D. B., \& Cable, D. M. (2003). Firm reputation and applicant pool characteristics. Journal of Organizational Behavior, 24, 733-751.

Uggerslev, K. L., Fassina, N. E., \& Kraichy, D. (2012). Recruiting through the stages: A meta-analytic test of predictors of applicant attraction at different stages of the recruiting process. Personnel Psychology, 65, 597660.

Wanous, J. P., Reichers, A. E, \& Hudy, M. J. (1997). Overall job satisfaction: How good are single-item measures? Journal of Applied Psychology, 82, 247-252.

RECEIVED 10/14/16 ACCEPTED 3/7/17 